TATIANA KRYuKova

MARIA SAPOROVSKAYA

E-MAIL: TAT.KRUKOWA44@GMAIL.COM

\title{
СОВЛАДАНИЕ В РОССИЙСКИХ СЕМЬЯХ: ИНДИВИДУАЛЬНЫЕ И ГРУППОВЫЕ ТЕНДЕНЦИИ
}

\section{Введение}

Сейчас, когда семья как системная часть общества меняется во всем мире, трудно сохранять экспертность по отношению к ней, приходится признавать, что мы многого не понимаем и не знаем. Это ставит новые задачи, среди которых и понимание медленных изменений современной семьи и брака. Немаловажной задачей мы считаем изучение возможностей семьи выживать, справляться с трудными ситуациями, развиваясь при этом.

\section{Совладание со стрессом}

Совладающее со стрессом (трудной жизненной ситуацией) поведение - важная сторона процесса социальной адаптации у здоровых людей. Это особое социальное поведение субъекта обеспечивает продуктивность, здоровье и благополучие человека. Совладающее поведение является целенаправленным поведением, позволяющим человеку справляться со стрессом и трудной жизненной ситуацией способами, адекватными личностным особенностям и ситуации (Крюкова, 2004, 2010; ред. Журавлев и др., 2008). Именно осознанный личный выбор стратегий поведения характеризует совладание как поведение субъекта и позволяет нам использовать данную методологию как основу нашего исследования: С.Л. Рубинштейн, К.А. Абульханова, А.В. Брушлинский и др.

Совладание со стрессом обеспечивает человека продуктивностью, хорошим здоровьем, благополучием, в том числе, в его близких 
взаимоотношениях, благодаря самостоятельному и сознательному осмыслению и рефлексивному переживанию стрессовых событий, выбору способов поведения при стрессе, адекватных личностным особенностям человека, динамике и социо-культурному контексту ситуации, а также отношений (ценности, нормы, т.д.). В этом случае целостный субъект, интегрирующий все виды деятельности и активности, способен быть независимым, самостоятельно совладающим с жизнью творцом, а не продуктом собственной биографии, что и составляет его сущность - творческую, нравственную, свободную (Брушлинский, 2003).

Совладание выступает как индивидуальный и как групповой феномен, значимый референт социального адаптивного поведения человека. Известно, что последствиями неблагоприятных воздействий на семью, в одних случаях, являются различные деструктивные явления (нарастание конфликтов, неудовлетворенности семейными отношениями, аддикции, одиночество, нередко распад семьи). Однако в других случаях происходит укрепление семейной общности (coherence) усиление сплоченности, выработка «психологического иммунитета» у членов семьи к неблагоприятным влияниям социума. Семьи в этой логике анализируются по уровню жизнестойкости (resilience), (Maddi, S.; McCubbin H.I. et al. 1997). Различная резистентность семей к действию стресса, вероятнее всего, объясняется действием копинг-механизмов, обеспечивающих эффективность социально-психологической адаптации членов семьи.

\section{Стресс и совладание в расширенных (трехпоколенных) семьях}

В современной психологической науке и практике возникла острая потребность в изучении особенностей семей, в которых присутствует и активно участвует в жизнедеятельности третье поколение поколение Прародителей. Рост числа расширенных семей в Европе и Америке является следствием мирового экономического кризиса начала XXI-го века. Каждый шестой американец является членом расширенной семьи, это более чем $10 \%$-ное увеличение численности данного типа семей с начала Великой рецессии в 2007 году. Объединение нуклеарных семей родителей и детей позволяет людям более 
успешно совладать с кризисной ситуацией в экономике (Brown 2008; Bailey Fong 2010; Porterfield 2009; George 2008; Lowenstein, Katz 2012; Roodin 2011; Vanderven 2008; Whitehouse, Whitehouse 2011).

Несмотря на традиционную склонность российской семьи к многопоколенной структуре, распространение расширенных семей в России в последние два десятилетия так же связано с негативными социальными и экономическими процессами, а именно, сложным материальным положением, особенно молодых семей и семей пенсионеров, и жилищной проблемой (результаты опроса НИИ семьи Министерства социальной защиты России, 2013). Многопоколенные или расширенные семьи составляют сейчас треть всех семей в России.

Нередко молодые (супружеские) семьи входят в структуру родительской семьи из-за отсутствия собственного жилья. Ранний возраст вступления в брак (18 - 22 года) способствует сохранению не только экономической и материальной, но и психологической зависимости взрослых детей от родителей. Проникновение и доминирование индивидуальных ценностей над групповыми приводит к тому, что жизненные цели, связанные с построением карьеры, становятся более приоритетными по сравнению с задачами воспитания детей, что способствует активному вовлечению прародителей в этот процесс.

Следует признать, что распространение расширенных семьей в современном обществе, в большей степени, является следствием деструктивных процессов и призвано помочь людям решать задачи, связанные $c$ выживанием. Это порождает особые проблемы - недостаточную удовлетворенность межличностными отношениями; переживание субъективного одиночества; конкуренцию между родителями и прародителями (особенно в сфере воспитания детей); конфликтность; распространение внутрисемейных коалиций; борьбу за власть - что, в целом, повышает уязвимость расширенных семей к внутренним и внешним стрессам (Сапоровская 2012).

Современное российское общество демонстрирует отход и отказ от коллективистической культуры. Анализ социо-культурного контекста наших исследований показывает, что в России коллективизм, в основном, характеризует поколения, рожденные в СССР, но не молодые поколения 90-х (различия в выраженности коллективизма/ индивидуализма значимы при р< 0.01), которые вынуждены присоединяться к индивидуалистическим культурным ценностям и нормам (Krюkova 2012). Реально сложилась ситуация, в которой явно 
просматривается отказ от Традиции (в широком значении слова), но индивидуалистическая культура не типична для России. Несмотря на явный межпоколенный разрыв, существует возрастающий у нового поколения интерес к опыту и достижениям предшествующих поколений (О. М. Здравомыслова, А.В. Мудрик), что является важным условием интеграции, стабилизации, прогрессивного развития общества. Семья, особенно расширенная, еще по-прежнему остается в России той социальной группой, в которой сильна Традиция, а механизм преемственности хоть и приобрел признаки противостояния и напряженности, но не сводим только к конфликту.

Таким образом, социальная значимость и актуальность исследования расширенных семей и, особенно, совладания в контексте межпоколенного взаимодействия, очевидны.

Наше исследование включало две стратегии: 1) изучение закономерностей межпоколенного наследования особенностей совладающего поведения в расширенных семьях (Исследование 1); 2) исследование стрессов и специфики совладания представителей разных поколений в расширенных семьях (Исследование 2).

Исследование 1. При изучении закономерностей межпоколенного наследования особенностей совладающего поведения в расширенных семьях в качестве эмпирического эквивалента мы рассматривали совпадение характеристик совладания в опыте Прародителей, Родителей и Детей. Выборку исследования составили представители поколения Прародителей, Родителей и Детей (юноши и девушки в возрасте 15-17 лет) в семье. Для решения исследовательских задач был использован Репертуарный тест ролевых конструктов (Дж. Келли). Конструктами репертуарных решеток являлись способы совладания (копинг-стратегии).

В первую очередь мы отследили те стратегии, которые представлены в опыте трех поколений членов семьи, это: Стремление принадлежать и Поиск духовной опоры. Опыт использования этих копинг-стратегий воссоздается по женской линии, при этом частота совпадений в межпоколенной динамике увеличивается. Эта закономерность характерна как для девушек, так и для юношей.

Ряд копинг-стратегий (Фокусирование на решении проблемь; Упорная работа и достижения; Ставка на близких друзей; Разрядка) воспроизводятся как из материнского, так и из отцовского опыта. Стратегия Поиск общественной поддержки и Беспокойство (стремление поделиться своей проблемой с другими людьми, заручиться их 
поддержкой, одобрением, советами) воспроизводится испытуемыми только из материнского опыта совладающего поведения. Опыт использования стратегий Общественные действия, Обращение за помощью к профессионалу, Стремление отвлечься и отдохнуть воспроизводится только по отцовской линии. Из опыта совладающего поведения бабушек передается копинг-стратегия Игнорирование проблемьь.

В рамках качественного исследования «наследования» копинга в семье мы проанализировали эссе респондентов на тему «Как они выживали». Категориями контент-анализа стали ответы на следующие вопросы:

- какие конкретно паттерны совладающего поведения предков являются для потомков образцами для подражания?

- какие элементы опыта предка хотел бы воспроизвести потомок в своем опыте?

Анализ описаний того, что хотели бы они воссоздать из совладания предков в собственном опыте, показал, что стратегии Оптимизм и Юмор воссоздаются потомками чаще, а вот стратегии проблемно-орентированного копинга предков, то есть их способы решения проблем - нет. Это, безусловно, чрезвычайно важный факт. Копинг предков, который чаще всего вызывает положительную оценку потомком, вызывает у них чувства уважения и восхищения, осознанно ими не воссоздается, что, однако, не исключает возможности его бессознательного воспроизводства.

Еще одним чрезвычайно важным фактом, полученным при анализе нарративов, оказалось то, что во всех работах, где отсутствовало описание чувств к предкам, так же полностью отсутствуют указания на воссоздание потомками элементов опыта совладания предков. Это говорит о том, что положительные эмоции и чувства потомков к предкам являются важным условием межпоколенной передачи опыта совладающего поведения в семье.

Исследование 2. С помощью феноменологического интервью мы выделили специфические трудности межпоколенного взаимодействия в расширенных полных и неполных семьях.

1. Типичной для расширенной семьи является конфронтация и конкуренция представителей поколений Прародителей и Родителей в сфере воспитания ребенка (из выборки 61\% прародителей и $57 \%$ родителей указывали на конкуренцию друг 
с другом в данной сфере), что имеет ряд негативных последствий для ребенка, а именно:

- ослабление контроля, отстраненность ребенка от жизни семьи, переживание им чувства субъективного одиночества;

- нечувствительность или отвержение личностных, поведенческих изменений, которые происходят с ребенком в процессе взросления, что вызывает у него протестные реакции, усиливающие межпоколенный конфликт в семье;

- вовлеченность ребенка во внутрисемейные коалиции (с Матерью против Отиа или с Бабушкой против Матери), что обостряет его конфликтные отношения с другими членами семьи и способствует формированию чувства вины перед ними.

2. Для расширенной семьи характерна борьба за власть (другими словами «кто главнее»). Особенно это проявляется в сфере воспитания ребенка (из выборки 63\% прародителей и $71 \%$ родителей указывали на это), что приводит к ролевой конкуренции, диффузности ролевой структуры семьи, неопределенности функций и статуса поколений в семье, что может затруднять процесс формирования и укрепления поколенной идентичности членов семьи. Борьба за власть в сфере воспитания наиболее характерна для расширенных неполных семей. Бабушка включена в воспитательный процесс в роли замещающего родителя и конкурирует со своей дочерью, которой одновременно принадлежат амбивалентные роли (мать и дочь), что повышает риск развития к внутриличностного конфликта.

3. Ядром межпоколенного взаимодействия в расширенных семьях является диадическое взаимодействие (Бабушка - Мать; Мать - Ребенок; Бабушка - Ребенок и т.д.) - в неполных расширенных семьях это проявляется в 75\% случаях, а вот в полных расширенных только $32 \%$. В таких случаях другие подсистемы отношений находятся на периферии, что обостряется межпоколенный конфликт и у членов семьи усиливается чувство неудовлетворенности межличностными отношениями.

4. Женщины поколения Прародителей в неполных расширенных семьях ощущают больший психологический комфорт, чем в полных семьях. Бабушки в полных расширенных семьях указывают на чувство одиночества в семье, на то, что их усилия и вклад в жизнь семьи недостаточно оценен другими членами 
семьи. Это приводит к усилению состояния неудовлетворенности и нервно-психического напряжения. Бабушки в неполных семьях ощущают свою востребованность и важность вклада в жизнедеятельность семьи.

5. В полных расширенных семьях трудности во взаимодействии у ребенка возникают с представителями всех поколений - c бабушками, дедушками, родителями. В неполной расширенной семье трудности, главным образом, проявляются в материнско-детском взаимодействии.

6. 6.Мужчины поколения Прародителей отмечают трудности при взаимодействии с женщинами поколения Родителей и внуками. С мужчинами поколения Родителей у них складываются отношения солидарности, взаимопонимания и взаимоподдержки. У мужчин поколения Родителей трудности во взаимодействии чаще возникают с женщинами поколения Прародителей и собственными детьми.

В целом, необходимо отметить, что межпоколенное взаимодействие в расширенных семьях потенциально является источником стресса для всей семьи как группы.

Анализ характеристик совладающего поведения представителей разных поколений в расширенных полных и неполных семьях показал:

\section{Полная расширенная семья}

- мужчины поколения Прародителей в трудных ситуациях межпоколенного взаимодействия более склонны к дистанцированию и отвлечению ( $p=0.02)$, что позволяет им максимально снизить свою ответственность за исход конфликтной ситуации в семье;

- женщины поколения Прародителей предпочитают эмоционально-фокусированный копинг ( $p=0.001)$, что усиливает их нервно-психическое напряжение;

- мужчины поколения Родителей в трудных ситуациях межпоколенного взаимодействия более склонны к уходу в профессиональную деятельность $(p=0.04)$, что позволяет им отдалится от конфликтной ситуации в семье;

- женщины поколения Родителей предпочитают проблемно-ориентированный копинг ( $p=0.01)$, что в значительной степени 
повышает их нагрузку и ответственность за качество межпоколенного взаимодействия в семье.

Неполная расширенная семья

- женщины поколения Прародителей предпочитают проблемно-ориентированный (при $p=0.003)$, и/или конфронтативный копинг $(p=0.001)$, что усиливает риск развития хронического конфликта в семье;

- женщины поколения Родителей предпочитают проблемно-ориентированный копинг и/или уход в работу $(p=0.01)$;

- дети (подростки) предпочитают конфронтативный копинг ( $p=$ 0.02), или копинг, ориентированный на социальную поддержку $(p=0.001)$.

Таким образом, можно сказать, что копинг в неполной расширенной семье более конгруэнтный, чем в полной расширенной семье. Это, однако, не гарантирует большую эффективность совладания семьи. Более важным результатом является то, что проблемно-ориентированное совладание в семье демонстрируют женщины поколения Родителей, что определяет их значительный вклад во взаимодействие поколений в семье, в формирование межпоколенной толерантности и милосердия.

\section{Совладание с переживаниями стресса в близких отношениях партнеров (супругов).}

Ряд авторов отмечает, что близкие диадические, в том числе, супружеские и романтические отношения качественно отличаются от других видов человеческих отношений тем, что прогрессивно влияют на развитие человека (Vangelisti; Reis; Fitzpatrick 2002; Mikulincer и Goodman 2006; Bershied, Mayers 2000, 2005). В тоже время близкие отношения в диаде партнеров нередко служат источником острого стресса и даже психологической травматизации личности (Jung; Burney; Skinner 1992). В связи с этим возникает вполне логичный вопрос: почему в одном случае близкие отношения способствуют развитию человека, а в другом наносят ему психологическую травму? 
Нами проведены исследования совладания со стрессами в близких (супружеских и романтических) отношениях при переживании одиночества в семье и в ситуации системного кризиса отношений - измены. Эта сфера явно недооценена пока наукой.

\section{Совладание с одиночеством в семье}

Мы выясняли, в какой степени одинокие люди, живущие в семье и без семьи, различаются в выборе копинг-стратегий. Выборка составила 286 человек в возрасте 18-56 лет. Методами диагностики были: опросники UCLA (Russell, Peplau); Loneliness Scale (de Gierveld, van Tilburg, 1999); копинг-шкалы - CISS (Endler, Parker, 1990); WCQ (Lazarus, Folkman, 1988), ACS (Frydenberg, Lewis, 1993), интервью.

Под одиночеством мы понимаем, с одной стороны, дефицит в отношениях (количественный и качественный), удовлетворяющих потребности человека; с другой стороны, мощный источник саморазвития и творчества (Zeidner, Saklofske 1996; Крюкова 2010).

Наши результаты показали, что люди, находящиеся в браке, более субъективно одиноки, чем те, кто живет один или с родителями (что типично дл России): различия значимы ( $\mathrm{p}=0.04)$, особенно по шкале эмоционального одиночества. Супруги страдают от одиночества в большей степени, чем живущие в одиночку (Крюкова, Ронч 2012), а их копинг-стратегии менее продуктивны. Наши данные подтверждают, что копинг с одиночеством детерминирует психологическое благополучие и здоровье субъекта. Подростки говорят о более высоком уровне одиночества, чем взрослые в семье. Они остро переживают одиночество и потому, что не владеют необходимыми социальными навыками, и в связи кризисным периодом развития своих отношений с другими. Но в целом одиноких взрослых в семьях больше, чем подростков. Обнаружено использование подростками непродуктивных копинг-стратегий. Взрослые члены семьи обычно не ищут поддержки других, когда испытывают стресс $(\mathrm{R}=-0.550, \mathrm{p}<0.0001)$.

Можно заключить, что уровень одиночества связан с возрастом и качеством социальной поддержки. Результаты поддерживают идею о социо-культурном и психологическом кризисе в российском обществе: росте отчуждения, враждебности, негативизма к власти и друг к другу, даже в семье, потере чувства принадлежности (аффилиации), 
особенно в мегаполисах. Социальное одиночество расширяет свои территории.

\section{Совладание с переживанием измены в близких отношениях}

Наиболее стрессогенной, связанной с чувствами ревности и ненависти для партнеров является ситуация измены, также характерная для динамики близких отношений (R. Sternberg, 1997; Шипова Н.C., 2014). Измена рассматривается как системная ситуация кризиса в супружеских или партнерских отношениях: субъективно понимаемый, отрицательно оцениваемый поведенческий акт партнера, нарушающий обязательство верности, вызывающий сильные, негативные эмоциональные переживания, и разрушающий доверие партнеров друг к другу; при котором один из партнеров переносит характеристики актуальных отношений и способы поведения в них на отношения с другим романтическим партнером. Последствия измены неоднозначны: она может привести как к улучшению отношений, так и к их ухудшению. Предполагалось, что переживание измены в романтических отношениях и совладание с ней обладает определенной спецификой и динамикой. Участниками выступили мужчины и женщины, которым изменил партнер, и другая группа, в которую вошли те, которые изменили своему партнеру. Методы: WCQ (Р. Лазарус и С. Фолкман в адаптации Т.Л. Крюковой и др., 2003); феноменологическое интервью. Респондентами были мужчины (22 человека) и женщины (25 человек) в возрасте 19-45 лет (средний возраст 32 года). С партнером испытуемых связывали чувства привязанности, присутствовали сексуальные отношения. Все 100\% испытуемых рассматривают измену как стресс, ее переживание как трудный период в своей жизни. Респонденты заявляют о длительных переживаниях (более двух лет) в $38 \%$ случаев, от года до двух - в 19\%, и 43\% испытывает острый стресс менее года. На основе анализа интервью в динамике переживания измены можно выделить три блока переживаний: 1) блок получения информации и реакции на нее (удивление, непонимание); 2) блок эмоций, связанных с партнером (разочарование, обида, гнев); 3) блок эмоций, связанных с отношениями (отчаяние, страх потери). Уже на первом этапе получения информации переживание может осложняться включением психологических защитных механизмов. В 
соответствии с полученными нами ранее данными механизм отрицания выражен на 72\%, что объясняется особенностями ситуации: субъект, не готовый к конструктивным действиям и не способный эффективно действовать, будет отрицать сам факт наличия проблемной ситуации и сильного эмоционального ее переживания. Выявлено влияние проекции, как механизма психологической защиты на усиление негативных последствий переживания измены в межличностных отношениях. Получена более полная картина переживаний партнеров, включающая не всегда осознаваемые компоненты этих переживаний, а также расширены представления о переживаниях, порожденных стрессом измены.

Выделено несколько особо травмирующих факторов в ситуации измены: ситуация соперничества, снижение самооценки, угроза разрыва значимых отношений и потери близкого человека, необходимость перестройки собственной жизни, разрушение диады и появление триады. Показателем сильного стресса также выступает изменившееся поведение испытуемых, его отмечают у себя 63\% опрошенных: поменялся режим сна и приема пищи, появились вредные привычки (курение, алкоголь), обострение соматических заболеваний, изменился стиль общения, появилось стремление к рефлексии и самокритике, стали уделять больше времени себе, появилось желание выразить себя в творчестве. В перечисленных изменениях поведения видится переоценка ценностей испытуемыми и предпосылки будущих стратегий совладания.

Большую роль в совладании (у 73\% выборки) играет социальная поддержка, т.к. испытуемые говорят о сложности самостоятельного преодоления ситуации. Основная поддержка заключалась в нахождении рядом, выслушивании и попытках изменить оценку ситуации, дать совет. В описаниях присутствуют в основном избегающие стратегии (старание переключиться на другие дела; уход в работу, религию; общение; употребление алкоголя; лишение себя свободного времени; отвлечение на детей; применение антидепрессантов). Стратегии проблемно-ориентированного (посещение консультаций психолога, анализ ситуации) и эмоционально-ориентированного копинга (выяснение отношений, погружение в переживания) применяются значимо реже. 


\section{Индивидуальный и диадический (совместный) копинг.}

Результаты показывают особенности стресса, порождаемого изменой в близких отношениях, с которым сложности самостоятельно совладать. У супругов распространены мало эффективные копинг-стили и стратегии - виды избегания, что говорит о высокой вероятности несовладания с данной трудной жизненной ситуацией.

Одним из принципиальных результатов исследования является вывод о том, что в диадическом совладании с ситуацией измены преобладает конфликтный стиль, уход в собственные переживания и интересы. Неверность партнера связана с длительным переживанием стресса, злости, ярости, ненависти, уязвленности, разочарования и т.д. В данной ситуации больше помогает индивидуальный копинг, так как совместные усилия супругов нередко заблокированы. Индивидуальные и диадические копинг-стратегии/стили слабо взаимодействуют у партнеров в ситуации измены. Хотя надо признать, что диадический копинг включает в себя одновременно организацию различных уровней действий семьи, укрепляет внутрисемейное единство и сплоченность, является процессом достижения баланса семейной системы, продвигает личностный рост и развитие членов семьи (McCubbin et al. 1997).

В целом, измена влияет не только на психологический комфорт участников отношений, но и на характеристики самих отношений. Проведенный регрессионный анализ выявил отрицательное влияние переменных, выражающих переживание ситуации измены партнера на стабильность их отношений $(\mathrm{R} 2=0,96, \beta=-0,34$ при $\mathrm{p} \leq 0,01)$. Таким образом, субъект, переживающий измену партнера, испытывает преимущественно негативные чувства, что способствует снижению значимости взаимоотношений для него и приводит к возможности их разрушения. Тем самым подтверждается стрессогенность измены через выраженность «угрозы разрушения значимых отношений». Полагаем, одним из показателей эффективности совладания выступает прощение неверного партнера, чувство любви к нему. 12\% выборки заявили о полном прощении партнера или спокойствии, равнодушии по отношению к нему. 47\% выборки говорят о невозможности его простить. После произошедшей измены отношения партнеров могут претерпевать различные трансформации: стать дружескими или враждебными вместо романтических, любовных. 
Таким образом, измена воспринимается всеми испытуемыми как трудная жизненная ситуация: переживание измены обладает яркой динамикой, результатом усилий субъекта может стать более или менее успешное совладание, которое влечет за собой изменение характеристик самих отношений. Зачастую измена и несовладание с ней играют негативную роль в динамике супружеских отношений и приводит к их разрыву, так как по результатам исследования большинство пар все-таки распадается.

\section{Заключение}

Стрессовые переживания в семье, связанные с взаимоотношениями, имеют свою специфику: не всегда понимаемую значимость для человека, опасность для его благополучия и самих отношений, длительность протекания, сочетание остроты и хроники, суженность сознания, непонимание себя и другого. Совладание со стрессами (relations-oriented coping) в таком контексте также специфично: более напряженно; менее эффективно и продуктивно, требует совместных усилий, которые не всегда эффективны; иногда коррелирует с искаженными оценками себя и ситуации; цели копинга смещены.

Имеются тенденции к несовладанию и/или непродуктивному совладанию с состояниями стресса подобного типа в семье: межпоколенные конфликты, трудные, порой неразрешимые ситуации (измена), одиночество в отношениях, избегание совместности, насилие.

В целом, российские семьи совладают со стрессами ежедневной жизни, многие проявляют высокий уровень жизнестойкости и закаленности, обладают немалыми внутренними ресурсами, что не исключает огромного количества плохо совладающих семей. Вопрос, который неизбежно встает при этом: какова «цена» совладания? Данный вопрос ждет своих исследователей.

\section{Библиография}

Брушлинский А.В. (2003), Психология субъекта / Отв. ред. В.В. Знаков. - М.: Институт психологии РАН; СПб.: Алетейя

Крюкова Т. Л. (2010), Психология совладающего поведения в разные периоды жизни: Монография.- Кострома: Изд-во КГУ им. Н.А. Некрасова 
Kryukova T. (2012), Cross-cultural Context of Stress-Coping Research. Paper / Abstracts of the XXX International Congress of Psychology. Cape Town, South Africa, July 2227, 2012. Published under the auspices of the International Union of Psychological Science (IUPsyS) / Ed. by Norman Duncan. P. 223.

Крюкова Т.Л., Ронч А.М. (2012), Детерминанты одиночества и совладания с ним в супружеских отношениях // Вестник Костромского государственного университета им. Н.А. Некрасова: - Кострома Т. 18, № 4. С. 129-134.

Крюкова Т.Л., Сапоровская М.В., Куфтяк Е.В. (2005), Психология семьи: жизненные трудности и совладание с ними. - СПб: Речь

Сапоровская М. В. (2012), Психология межпоколенных отношений в современной российской семье. - Кострома: КГУ им. Н. А. Некрасова

Совладающее поведение: Современное состояние и перспективы (2008), / Под ред. А.Л. Журавлева, Т.Л. Крюковой, Е.А. Сергиенко - М.: Изд-во „Институт психологии Российской Академии Наук”

Шипова Н.С. (2014), Совладание с переживанием измены в близких отношениях. Дисс ....кан. психол. Наук. Кострома: КГУ им. Н.А. Некрасова

Berscheid, E., Regan, P.C. (2005), The psychology of interpersonal relationships. Pearson Prentice Hall

Couples coping with stress. Emerging Perspectives on Dyadic Coping (2005), / Ed. by Revenson, T.A., Kayser, K., Bodenmann, G. - APA: Washington, DC

McCubbin H.I., McCubbin M.A., Thompson A.I., Han S.-Y., Allen C.T. (1997), Families under stress: what makes them resilient, AAFCS Commemorative Lecture. http:// www1.cyfernet.org/prog/fam/97-McCubbin-resilient.html [24.05.2014]

Sternberg, R. J. (1997), When love stories become love traumas, Yale University 


\section{SUMMARY}

\section{Coping in Russian Families: Individual and Group Tendencies}

The aim of the study is to investigate the ever referent for any society sociocultural and socio-psychological problem: how do people in Russia survive nowadays in transforming culture and family? Multigenerational families' gap and resources are analyzed. The authors are trying to give an answer to difficult questions: do couples cope with emotional problems nowadays: cheating, jealousy, loneliness? What coping strategies do families choose and how productive they are.

Keywords:

coping, family, generation, culture in transformation 